\title{
Duration of attention: The perceptual deprivation effect
}

\author{
BRUCE T. LECKART, ${ }^{1}$ JOSEPH R. LEVINE, CHRISTINE GOSCINSKI, AND WILLIAM BRAYMAN \\ SAN DIEGO STATE COLLEGE
}

College students viewed 18-sided randomly generated polygons. They were told to attend to each form until they "finished looking at it." Before each stimulus presentation, $2,16,30$, or $44 \mathrm{sec}$ of perceptual deprivation was administered. The results indicated that there was a direct relationship between the duration of perceptual deprivation and the duration of attention. The results were interpreted in terms of the deprivation establishing a need for stimulation that is satisfied by attending.

During the last 10 years there has been a renewed interest in attentional processes. One major body of research in this area has been concerned with determinants of the duration of attention under conditions in which the task-demand characteristics of the situation are minimal (Leckart \& Faw, 1968). Generally, research has indicated that this dependent variable, the duration of attention, is a function of both stimulus and organismic variables (e.g., Berlyne, 1958; Zamansky, 1956). One interpretation of these findings suggests that the duration of attention reflects the organism's need for stimulation and the stimulus's ability to satisfy the need. Accordingly, the long duration reflects a relatively high need for stimulation.

Another body of literature is concerned with the effects of the independent variables of sensory and perceptual deprivation on behavior. These studies have shown a dramatic increase in the S's search for, and attention to, stimuli as a function of deprivation (Schultz, 1965). One interpretation of these findings is that deprivation produces a need for stimulation. The present study was designed to establish an empirical relationship between these two bodies of research, which are apparently conceptually related through the concept of need for stimulation, by determining the effects of short-term perceptual deprivation on the duration of attention. It was expected that depriving human Ss of stimulation would increase their need for stimulation and therefore increase subsequent duration of attention. It was also hypothesized that there would be a

Fig. 1. Duration of attention as a function of perceptual deprivation. direct relationship between the duration of deprivation and attention.

\section{METHOD}

The 31 male and female college students who served as Ss were tested in a $6 \times 6 \mathrm{ft}$ lightproof chamber. They sat at a table facing a $12 \times 12$ in. rear-projection screen inserted in one of the walls. The screen was at eye level and about $2 \frac{1}{2} \mathrm{ft}$ from the S's face. They were told the experiment was to investigate changes in the galvanic skin response while viewing geometric forms. Sham electrodes were attached to two fingers of the left hand, and the Ss were told the leads were attached to a polygraph in the adjacent room. The Ss were told that their task was to attend to each of the geometric forms until they were "finished looking at it." The automatically projected forms were terminated by a button held in the S's right hand. The $12 \times 12$ in. forms were projected by a Kodak Carousal 800 projector. Neutral-density filters reduced the intensity of the projection by $90 \%$. Ss were shown 25 different 18-sided, randomly generated forms constructed according to Method I outlined by

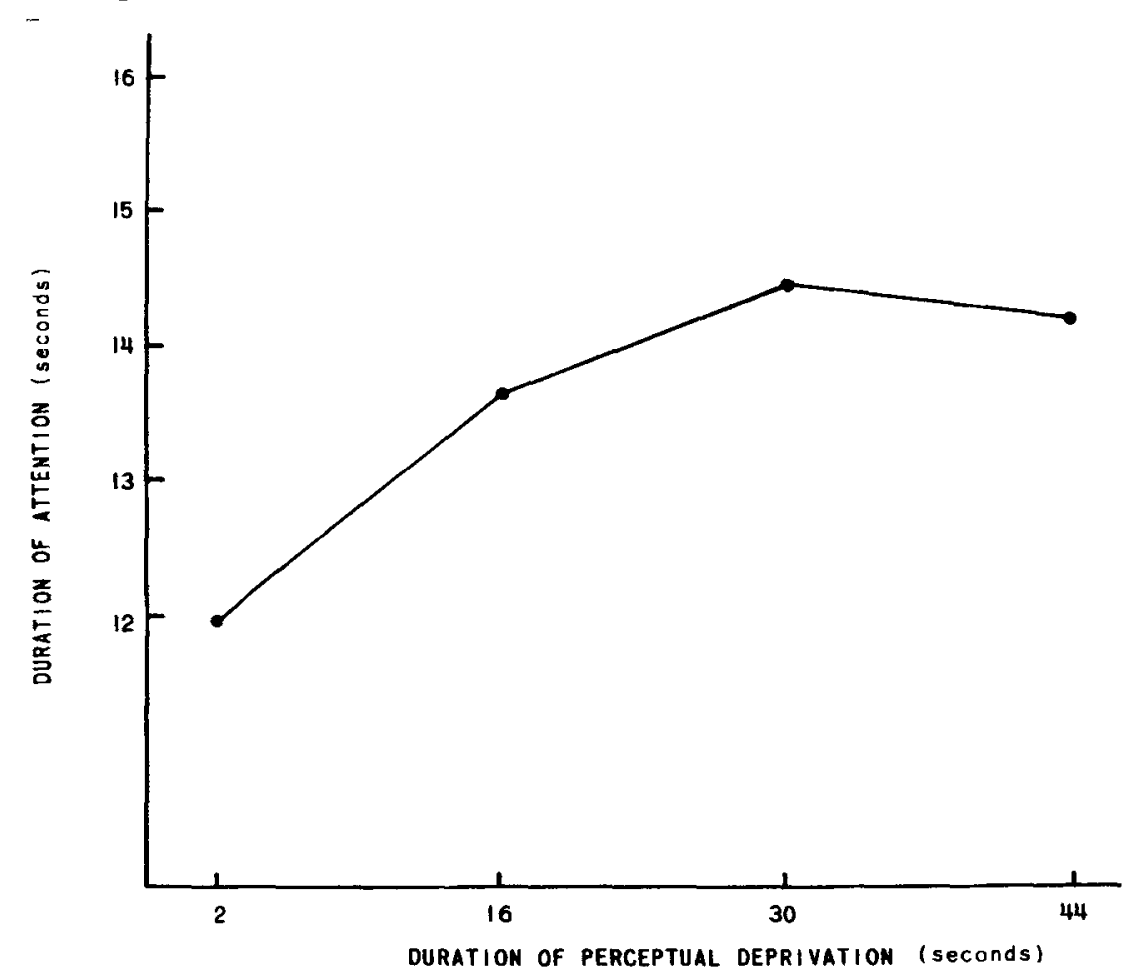

Attneave and Arnoult (1956). Four different interstimulus intervals (ISI), 2 , 16,30 , and $44 \mathrm{sec}$, were presented to each $S$ six times. Perceptual deprivation was defined as darkness during the ISI. A different random order of forms and a different random sequence of intervals was used for each $\mathbf{S}$. The durations of attention were automatically recorded.

\section{RESULTS}

For each S, four scores were calculated: the mean duration of attention to stimuli following perceptual deprivation intervals of $2,16,30$, and $44 \mathrm{sec}$. These means are presented in Fig. 1. An analysis of variance indicated a significant difference in the durations of attention as a function of the duration of the perceptual deprivation period $(F=7.14$, df $=3 / 90, p<.01)$. An inspection of Fig. 1 indicates that as perceptual deprivation increased from 2 to $30 \mathrm{sec}$ the duration of attention increased. However, increasing the deprivation period from 30 to $44 \mathrm{sec}$ produced no further increase in the duration of attention, but actually a slight decrease. 


\section{DISCUSSION}

The prediction that perceptual deprivation increases duration of attention is supported by comparing the results of the present experiment with similar previous experiments utilizing the same materials in which there was no perceptual deprivation. The average duration of attention in the present experiment was $13.2 \mathrm{sec}$ vs approximately $7 \mathrm{sec}$ in the previous experiments (e.g., Brown \& Lucas, 1966). Similarly, the results supported the prediction that as the duration of the perceptual deprivation period increases; the duration of attention increases. This finding establishes an empirical relationship between perceptual deprivation and the duration of attention. It further suggests that brief periods of perceptual deprivation establish a need for stimulation that is satisfied by attending for longer periods of time. ${ }^{2}$

The concept of maintaining an optimal level of stimulation or cortical arousal may provide a meaningful conceptual basis for future research in this area. According to this position, when the organism's level of cortical arousal is lowered by a reduction of stimulus input, he is required to attend for longer durations (thereby obtaining more stimulation) in order to raise the level of arousal to the optimum. Obviously, future research should be directed at evaluating the possible interpretations as well as further investigating the effect itself. Future research might also be directed at the effects of short-term perceptual deprivation. A great deal is known about the effects of long-term perceptual deprivation, but relatively little is known about the consequences of short-term periods of perceptual deprivation.

\section{REFERENCES}

ATTNEAVE, F., \& ARNOULT, M. The quantitative study of shape and pattern perception. Psychological Bulletin, 1956, 53, 452-457.

BERLYNE, D. The influence of complexity and novelty in visual figures on orienting responses. Joumal of Experimental Psychology, 1958, 55, 289-296.

BROWN, L. T., \& LUCAS, J. H. Supplementary report: Attentional effects of five physical properties of visual patterns. Perceptual \& Motor Skills, 1966, 23, 343-346.

KIMMEL, H. D., BOICE, C., \& LECKART, B. T. Paired comparison scaling of reaction potential from simultaneous measurements of GSR and looking time. Perception \& Psychophysics, $1969,5,294-296$.
LECKART, B. T., \& FAW, T. T. Looking time: A bibliography. Perceptual \& Motor Skills, 1968 , 27, 91-95.

SCHULTZ, D. P. Sensory restriction effects on behavior. New York: Academic Press, 1965. (P. 145)

ZAMANSKY, H. S. A technique for assessing homosexual tendencies. Journal of Personality, 1956, 24, 436-448.

\section{NOTES}

1. Address: Department of Psychology, San Diego State College, San Diego, California 92115. 2. Another possible interpretation of the results considers the difference in illumination between the stimulus presentation and the perceptual deprivation period. According to this interpretation, the $S$ s attend for longer durations after the longer perceptual deprivation periods because their eyes are more dark adapted and they must first adapt to the increase in light intensity before they can begin scanning the screen. However, the fact that Kimmel, Boice, and Leckart (1969) found an effect similar to the present one, when the level of illumination of the $S$ 's viewing screen was maintained between trials, suggests that the present finding does not depend upon differential dark adaptation.

(Accepted for publication June 30, 1969.) 